\title{
Correction to: Inaccurate Value at Risk Estimations: Bad Modeling or Inappropriate Data?
}

\section{Evangelos Vasileiou'}

Published online: 3 September 2021

(C) Springer Science+Business Media, LLC, part of Springer Nature 2021

\section{Correction to: Computational Economics https://doi.org/10.1007/s10614-021-10123-8}

Unfortunately the author's given name and family name were interchanged in the electronic version of this article. The article was updated and the name is now correctly displayed in the order given name followed by family name, i.e. Evangelos Vasileiou.

The original article has been corrected.

Publisher's Note Springer Nature remains neutral with regard to jurisdictional claims in published maps and institutional affiliations.

The original article can be found online at https://doi.org/10.1007/s10614-021-10123-8.

Evangelos Vasileiou

e.vasileiou@ba.aegean.gr

1 Department of Financial and Management Engineering, School of Engineering, University of the Aegean, 45 Kountouriotou Str, 82100 Chios, Greece 